\title{
ANÁLISE DO PROCESSO DE IMPLANTAÇÃO DAS COMPRAS PÚBLICAS SUSTENTÁVEIS DE UMA INSTITUIÇÃ̃O DE ENSINO SUPERIOR
}

Thayanne Alves Ferreira (Universidade Estadual do Maranhão) thayanne.eng@gmail.com Maxweel veras Rodrigues (Universidade Federal do Ceará) maxweelveras@gmail.com

\section{Resumo}

O objetivo geral deste estudo é analisar o processo de implantação das compras públicas sustentáveis da Universidade Federal do Ceará fundamentado em uma metodologia de compras públicas sugerida pelo governo federal. No desenvolvimento da pesquisa foi utilizada uma abordagem qualitativa e quantitativa. A etapa qualitativa exploratória foi realizada através de entrevistas semiestruturadas com servidores que participam do processo de compra da universidade. A metodologia é constituída de cinco etapas: planejamento; definição de metas e objetivos; construção do plano de ação; aplicação do plano e monitoramento dos resultados. As principais observações mostram que ainda não existe uma política de utilização de critérios de sustentabilidade no processo de compra da organização. Por motivo de cobranças dos órgãos fiscalizadores e medidas provisórias foi criado um plano de logística sustentável que traz vários aspectos relacionados à sustentabilidade, dentre eles, compras e licitações.

Palavras-Chaves: (Compras Públicas Sustentáveis. Gestão Pública. Sustentabilidade.)

\section{Introdução}

Em torno dos problemas ambientais estão envolvidas questões, econômicas e sociais. Existe uma preocupação em relação ao equilíbrio entre desenvolvimento e crescimento econômico. A resposta de como será encontrado esse equilíbrio deve ser demonstrada por todos os setores da sociedade, governos, universidades, comunidade, os quais devem buscar uma nova forma de relacionamento com o Planeta Terra.

O volume de compras realizadas pelas universidades públicas é expressivo. De acordo com Moura (2012), as compras públicas representam uma fatia substancial da economia de um país. Estima-se que esteja em torno de $8 \%$ a $25 \%$ do Produto Interno Bruto (PIB). No Brasil, as compras governamentais movimentam cerca de $10 \%$ a $15 \%$ do Produto Interno Bruto nacional em produtos e serviços, algo em torno de R $\$ 600$ bilhões. Esse volume de consumo vem fazendo a Administração Pública adotar critérios de sustentabilidade em suas contratações, induzindo indiretamente mudanças no padrão de produção e consumo.

Diante das transformações que a sociedade em geral vem enfrentando, é preciso que seja testado métodos de gerenciamento que priorizem a racionalização dos recursos e a 
preservação do meio ambiente através da utilização de critérios ambientais e disseminação de uma cultura de consumo consciente.

Entende-se que o processo de compras sustentáveis dentro das instituições de ensino resultará em impactos significativos na prestação de serviço e formações de futuros profissionais, mais compromissados com a preservação do planeta.

Por conseguinte, este artigo irá relatar o processo de implantação/execução das compras públicas sustentáveis da Universidade Federal do Ceará fundamentado no modelo de compras públicas sugerido pelo governo federal brasileiro. $\mathrm{O}$ artigo segue da seguinte maneira: a seção dois traz o referencial teórico; a seção três apresenta o aspecto metodológico do estudo; a seção quatro apresenta a análise do processo de implantação das compras públicas sustentáveis da Universidade Federal do Ceará; a seção cinco traz a conclusão do estudo

\section{Referencial Teórico}

\section{Políticas públicas de sustentabilidade: aspectos reguladores brasileiros}

No setor público brasileiro toda aquisição realizada com recursos públicos deve obedecer à Lei $\mathrm{n}^{\mathrm{o}}$. 8.666/93, que regulamenta e serve de base para os gestores.

A promoção do desenvolvimento sustentável passou a ser utilizado no capítulo $3^{\circ}$ da lei 8666/93, como uma das finalidades a que a licitações se dispõem. Carvalho Filho (2013) define licitação como o procedimento administrativo vinculado através dos quais entes da administração pública e aqueles por ela controlados escolhem a melhor proposta entre as oferecidas pelos diversos interessados, com dois objetivos: celebração dos contratos ou a obtenção do melhor trabalho técnico, artístico ou científico.

A Política Nacional de Mudanças Climáticas, Lei nº 12. 187, de 29 de dezembro de 2009, traz em seu artigo $6^{\circ}$ no inciso XII a possibilidade de se estabelecer critérios de preferências nas licitações em concorrências públicas, compreendidas as parcerias público-privadas e a autorização, permissão, outorga e concessão para a exploração de serviços públicos e recursos naturais, para as propostas que propiciem maior economia de energia, água e outros recursos naturais e redução da emissão de gases de efeito estufa e de resíduos (BRASIL, 2009).

Em janeiro de 2010, foi instituído uma Instrução Normativa que dispõem sobre os critérios de sustentabilidade ambiental, na aquisição de bens, contratações de serviços ou obras pela Administração Pública Federal. Em seu art. $1^{\circ}$ que tem como base o $\operatorname{artigo~} 3^{\circ}$ da Lei $n^{\circ} 8.666$, de 21 de junho de 1993, as especificações para a aquisição de bens, contratação de serviços e obras por parte dos órgãos e entidades da administração pública federal direta, autárquica e fundacional deverão conter critérios de sustentabilidade ambiental, considerando os processos 
de extração ou fabricação, utilização e descarte dos produtos e matérias-primas. (BRASIL, MINISTÉRIO DO PLANEJAMENTO, ORÇAMENTO E GESTÃO, 2013).

O Decreto Presidencial $n^{\circ} 7.746$, de 05 de julho de 2012, vinculado apenas aos órgãos da administração pública federal estabelece critérios, práticas e diretrizes para a promoção do desenvolvimento nacional sustentável nas contratações realizadas pela administração pública federal e institui a Comissão Interministerial de Sustentabilidade na Administração Pública (CISAP) (BRASIL, 2012).

Ainda de acordo com o decreto $\mathrm{n}^{\circ}$ 7.746, de 5 de junho de 2012, a administração pública federal direta, autárquica e fundacional e as empresas estatais dependentes deverão elaborar e implementar Planos de Gestão de Logística Sustentável, no prazo estipulado pela Secretaria de Logística e Tecnologia da Informação, prevendo, no mínimo: Atualização do inventário de bens e materiais do órgão e identificação de similares de menor impacto ambiental para substituição; Práticas de sustentabilidade e de racionalização do uso de materiais e serviços; Responsabilidades, metodologia de implementação e avaliação do plano; Ações de divulgação, conscientização e capacitação.

A figura 1 mostra um resumo das principais normas e leis brasileiras que estão ligadas as compras e contratações públicas sustentáveis.

Figura 1-Principais normas e leis brasileiras em relação às compras e contratações públicas sustentáveis

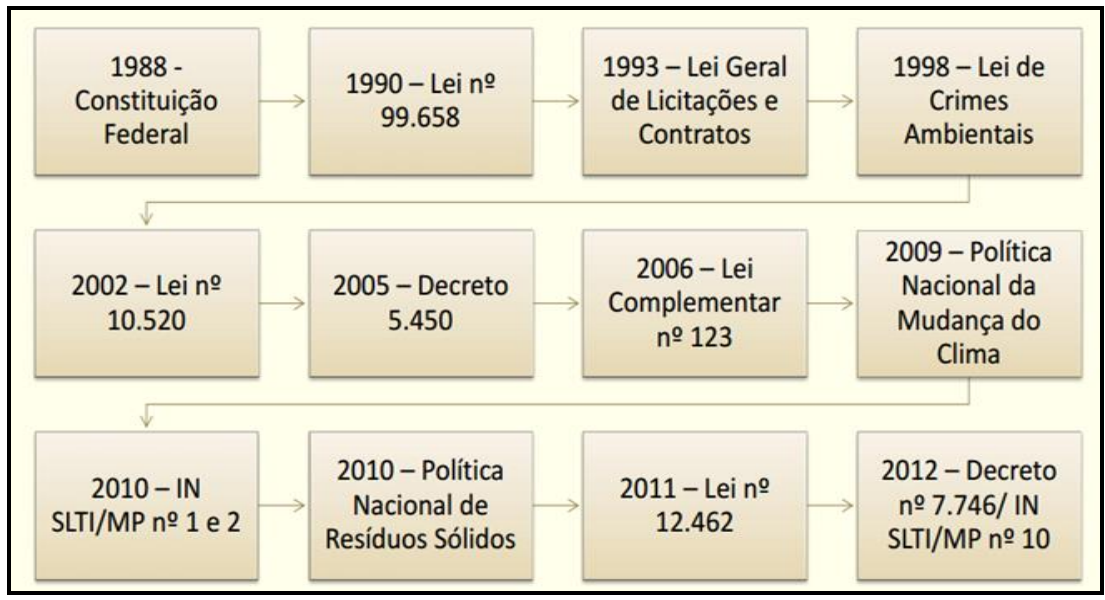

Fonte: Ministério do Planejamento, Orçamento e Gestão (2014).

No ano de 1988 foi aprovada a Constituição Federal do Brasil, considera a mais democrática em relação às anteriores outorgadas. Após esse marco legal, surgiram normas visando garantir o princípio da sustentabilidade das licitações, a saber: No ano de 1990 a lei n $^{\circ} 99.658$ é instituída, no âmbito da Administração Pública Federal, regulamentando o reaproveitamento, a movimentação, a alienação e outras formas de desfazimento de material. 
Lei ${ }^{\circ} 8.666$ de 21/06/1993 - Lei de Licitações e Contratos e Lei $n^{\circ} 9.605$ de 05/10/1998 - Lei de Crimes Ambientais; Lei $n^{\circ} 10.520$ estabelece a modalidade de licitação denominada pregão, para aquisição de bens e serviços comuns, e dá outras providências, o Decreto 5.450 regulamenta o pregão, na forma eletrônica, para aquisição de bens e serviços comuns, e dá outras providências.

No ano de 2006 a Lei Complementar $n^{\circ} 123$ é aprovada estabelece normas gerais relativas ao tratamento diferenciado e favorecido a ser dispensado às microempresas e empresas de pequeno porte no âmbito dos Poderes da União, dos Estados, do Distrito Federal e dos Municípios; Lei $N^{\circ} 12.187$, de 29 de dezembro de 2009 Institui a Política Nacional sobre Mudança do Clima (PNMC). A Instrução Normativa NO 01, de 19 de janeiro de 2010 dispõe sobre os critérios de sustentabilidade ambiental na aquisição de bens, contratação de serviços ou obras pela Administração Pública Federal. A Instrução Normativa nº 02, de 11 de outubro de 2010, estabelece normas para o funcionamento do Sistema de Cadastramento Unificado de Fornecedores no âmbito dos órgãos e entidades integrantes do Sistema de Serviços Gerais.

Em dois de agosto de 2010 é sancionada a Lei № 12.305, institui a Política Nacional de Resíduos Sólidos, dispondo sobre seus princípios, objetivos e instrumentos, bem como sobre as diretrizes relativas à gestão integrada e ao gerenciamento de resíduos sólidos, incluídos os perigosos, às responsabilidades dos geradores e do poder público e aos instrumentos econômicos aplicáveis. No ano de 2011 a Lei No 12.462 é regulamentada é institui o Regime Diferenciado de Contratações Públicas (RDC). Em 12 de novembro de 2012 a Instrução Normativa $n^{\circ} 10$, estabelece regras para elaboração dos Planos de Gestão de Logística Sustentável.

As ações que veem sendo desenvolvidas pelo governo brasileiro e governos internacionais servem para confirmar a importância da inclusão do tema das Compras Públicas Sustentáveis nas políticas governamentais. A adesão a critérios de sustentabilidade precisa ser resguardada por normas e leis que possam servir de base para utilização universal e institucional dos critérios ambientais.

\section{Metodologia}

Utilizou-se, neste trabalho, o método de estudo de caso que de acordo com Gil (2010) fundamenta-se em um estudo profundo e exaustivo de um ou de poucos objetos, permitindo seu amplo e detalhado conhecimento. O presente estudo busca obter dados ou informações sobre características, ações ou opiniões de determinado grupo de pessoas, por meio de um de instrumento de pesquisa. 
O objeto deste estudo foi um campus de uma universidade pública federal brasileira, Universidade Federal do Ceará, pelo motivo de ser uma das maiores universidades públicas do Brasil, por tanto uma instituição estratégica para o desenvolvimento do País. Dessa forma as ações de compras sustentáveis desenvolvidas por uma instituição desse nível podem influenciar de forma significativamente as demais instituições públicas da região.

Após analisar os principais modelos sobre a implantação das compras públicas sustentáveis, foi selecionado o modelo sugerido pelo governo federal brasileiro, do ICLEI-LACS (Governos Locais pela Sustentabilidade), que é uma associação internacional formada por governos locais e outras organizações governamentais que assumiu um compromisso com o desenvolvimento sustentável. O ICLEI-LACS desenvolveu no Brasil um trabalho em relação ao tema Compras Públicas Sustentáveis, que originou uma parceria com o Centro de Estudos em Sustentabilidade (GVces) da Fundação Getúlio Vargas para a publicação do "Guia de Compras Públicas Sustentáveis: uso do poder de compras do governo para a promoção do desenvolvimento sustentável”. O guia é uma tradução do manual Procura + , desenvolvido pelo ICLEI na Europa (ICLEI, 2010). O modelo segue a sequencias de algumas etapas, a figura xx mostra essas etapas de acordo como foram analisadas na pesquisa.

Figura 2-etapas da metodologia de implantação das compras públicas

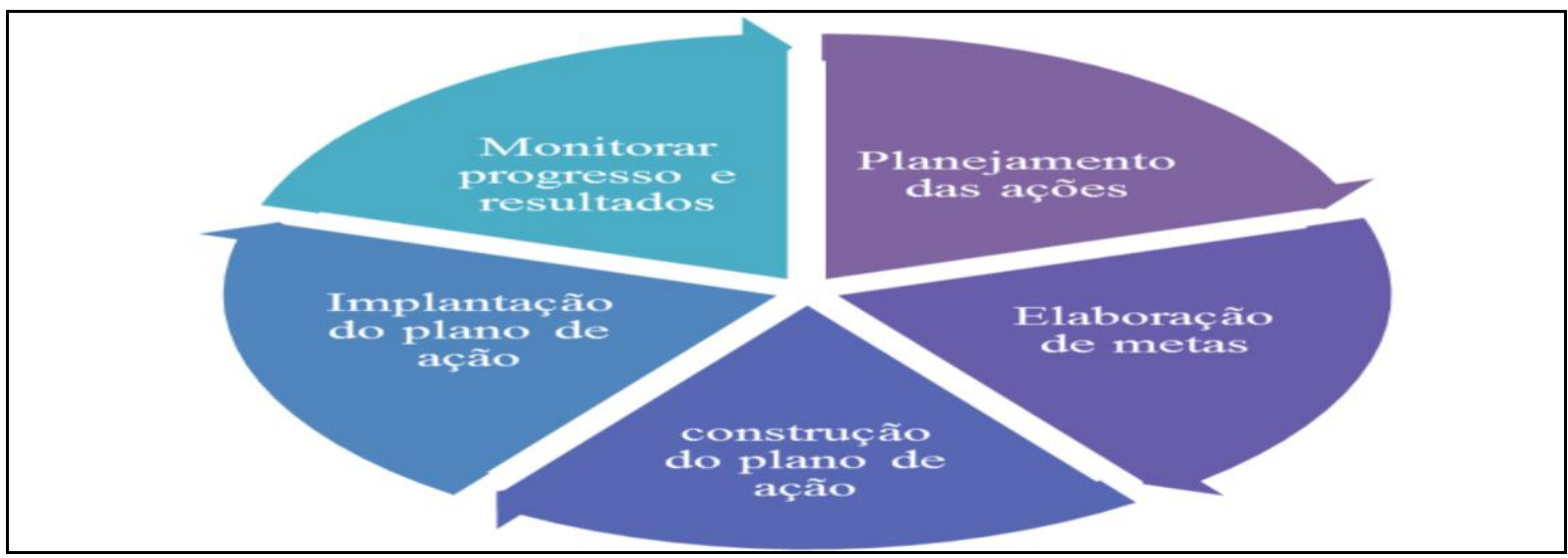

Fonte: elaboradas pelos autores com base em ICLEI

Utilizado como base o modelo sugerido pelo governo federal brasileiro, este estudo foi construído através de dados obtidos de entrevistas estruturadas. A entrevista é considerada um dos meios de coletas de dados mais importantes para estudos de caso, podendo ser usados em metodologias positivistas e fenomenológicas, com o objetivo de descobrir o que os entrevistados fazem, pensam ou sentem (COLLIS; HUSSEY 2005; YIN, 2010).

\section{Estudo de Caso}


A metodologia é baseada no uso de uma quantia de produtos sustentáveis comprados como um indicador fundamental. Cada autoridade ou organização pode determinar o que é exatamente um produto sustentável, desde que leve em considerações critérios como: analise do clico de vida, rotulagem ambiental, entre outros. Todos os produtos considerados sustentáveis devem ter uma justificativa sobre os critérios utilizados. Isso garante que as mais importantes melhorias ambientais estão sendo levadas em conta e torna possível calcular o benefício ambiental cumulativo da campanha (BIDERMAN et al., 2008). O modelo para a análise comparativa e constituída pelas etapas sugeridas na figura 2 e detalhadas nas próximas subseções.

\subsection{Planejamento das ações}

Quando analisadas as estratégias relacionadas às compras públicas sustentáveis utilizadas pela universidade pesquisada, observou-se que, a adoção das compras sustentáveis não vem acontecendo de maneira planejada ou apoiada em alguma metodologia. Percebe-se que ocorrem ações sem que exista uma política de compra sustentáveis ou uma estratégia definida. $\mathrm{Na}$ etapa qualitativa foi perguntado se existe uma política de compras sustentáveis estabelecida na universidade e como foi iniciado o processo de implantação das compras sustentáveis, algumas respostas foram:

[...] nas reuniões que a gente tem tido com o Reitor com o Pró-Reitor eles mostram a preocupação da administração superior é que a gente atenda a legislação nova que tá surgindo sobre compras sustentáveis. (E2)

[...] Tá sendo construída porque é algo novo, por exemplo, nos projetos a gente tem essa preocupação em prédios que não se utilize tanto a nossa energia clássica, sejam prédios mais arejados que você use menos ar condicionado menos energia artificial, se tenha mais janelas de vidro pra você ter a iluminação natural então é uma preocupação os entornos com áreas verdes. (E1)

[...] preocupação existe até por parte da fiscalização né, mais por parte da fiscalização como o TCU vem sempre batendo em cima da sustentabilidade aí eles estão tentando implementar mais isso agora depois de tanto tempo. (E4)

Durante a etapa quantitativa foi questionado sobre a frequência de utilização de critérios de sustentabilidade nos processos de compras e contratações de serviços da universidade, os dados coletados apontam que a utilização ocorre com mais frequência nos processos licitatórios de obras e engenharias. É possível observar que a utilização das compras sustentáveis tem tendência a ocorrer nos processos em que existe maior amparo legal em relação ao que pode ser exigido nos editais de licitações, como se verifica em trechos de entrevistas transcritas a seguir: 
[...] meu caso como eu não faço licitação de obra dentro do edital eu coloco alguns requisitos como: descarte do que resta na obra e tal se é regulamentado pela ABNT um monte de coisa que coloco da sustentabilidade que foi formulado por mim e pela Engenheira que era Pregoeira antes que o Mestrado dela foi nessa parte de obras sustentáveis. (E4)

A pesquisa em campo possibilitou a percepção e análise de algumas medidas que a instituição vem adotando para cumprir normas que vem sendo impostas pelo Governo Federal. A Instrução Normativa $N^{o} 10$ de 12 de novembro de 2012, que estabelece as regras para elaboração dos Planos de Gestão de Logística Sustentável.

O Plano de Logística Sustentável da universidade pesquisada foi elaborado por uma comissão instituída e por colaboradores da instituição. O plano foi divido nas seguintes etapas: Etapa 01 - Criação da Comissão Gestora e divisão dos servidores em grupos de trabalho para ajudar na elaboração; Etapa 02 - Construção de um diagnóstico geral da Instituição com o objetivo de buscar medidas socioambientais e socioeducativas dentro da UFC; Etapa 03 - Mensuração de recursos após suas devidas identificações usando as habilidades de cada grupo e os dados de inventário dos bens e materiais; Etapa 04 - Execução após a aprovação do Plano pelo Conselho Universitário ; Etapa 05 - Execução ; Etapa 06 - Monitoramento, a cada 6 meses, contados a partir da publicação, se for necessário, revisão de metas

De acordo com Biderman et al. (2008), o documento final deve: conter um claro retrato das atividades de aquisição, apresentar as respostas para as categorias de perguntas (importância organizacional, temas ambientais, quantidades do produto, informação financeira).

\subsection{Elaborações de metas}

Os objetivos e metas devem ser traçados de maneira que possam ser executados, indicar a porcentagem de produtos sustentáveis que serão adotados e o período em que os objetivos serão alcançados.

Os participantes da pesquisa responderam sobre o seu grau de conhecimento em relação às metas e objetivos para as compras sustentáveis. Os participantes da pesquisa responderam em relação ao seu grau de conhecimento em relação às metas e objetivos para as compras sustentáveis com o envolvimento desde a alta administração até os usuários finais. A figura 3 expõem os dados: 
Figura 3-Grau de conhecimento em relação aos procedimentos e estratégias

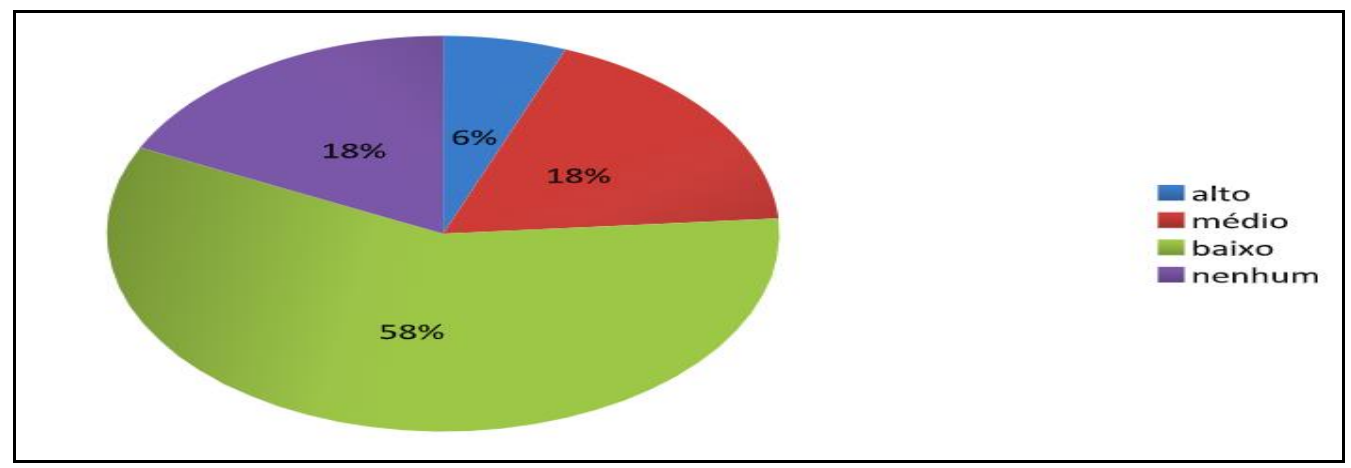

Fonte: Dados obtidos na pesquisa de campo com aplicação de questionário.

A pesquisa mostra que $58 \%$ dos entrevistados afirmam ter um baixo nível de conhecimento em relação aos objetivos e metas sobre compras públicas sustentáveis, enquanto $18 \%$ dizem não ter nenhum conhecimento.

A pesquisa mostra que não houve um envolvimento de todos os participantes do processo de compras da instituição.

As ações de compras sustentáveis existentes na instituição pesquisada são relacionadas ao Plano de Logística Sustentáveis: redução do consumo de energia elétrica e de água e esgoto; redução do consumo de papel A4, copos descartáveis e cartuchos de tintas para impressoras; gerenciamento dos resíduos sólidos, com foco na redução, reuso e reciclagem; programa de capacitação para servidores e terceirizados; realizar campanhas de conscientização de escolha por produtos mais sustentáveis e divulgar para toda a comunidade os produtos elencados na lista (UNIVERSIDADE FEDERAL DO CEARÁ, 2013a).

\subsection{Construção do plano de ação}

Para que ocorra a execução dos objetivos e metas é necessário seu entendimento, para tanto, é preciso descrevê-las. Para isso deve ser elaborado um plano de ação, fundamentado em estratégias definidas.

O plano de ação da universidade foi desenvolvido dentro do plano de logística sustentável para licitação sustentável de material de consumo. A instrução Normativa No 10/2012 que regulamenta e propõem diretrizes para criação do plano informa que os Planos devem conter: os objetivos; responsabilidade dos gestores; ações, metas e prazos de execução; mecanismo de monitoramento e avaliação das ações que serão implementadas. Após a elaboração dos objetivos e metas, a equipe elaborou um cronograma de implementação, resultados esperados e matriz de responsabilidades conforme mostra o quadro 1. 


\begin{tabular}{|c|c|c|c|c|c|}
\hline Iniciativas & Resultados esperados & $\begin{array}{l}\text { Unidade } \\
\text { Responsável }\end{array}$ & Servidor Responsável & $\begin{array}{l}\text { Data } \\
\text { Início }\end{array}$ & Data Fim \\
\hline 1 & $\begin{array}{l}\text { Padronizar a compra de materiais de } \\
\text { consumo com melhor desempenho } \\
\text { ambiental. }\end{array}$ & $\mathrm{CPL} / \mathrm{PRADM}$ & $\begin{array}{l}\text { Diretor da Comissão de } \\
\text { Licitação }\end{array}$ & & $\begin{array}{l}\text { Lista já está } \\
\text { elaborada }\end{array}$ \\
\hline 2 & Adquirir copos de papel reutilizáveis. & $\mathrm{CPL} / \mathrm{PRADM}$ & $\begin{array}{l}\text { Diretor da Comissão de } \\
\text { Licitação }\end{array}$ & 2014 & $\begin{array}{l}\text { Atividade } \\
\text { continua }\end{array}$ \\
\hline 3 & Adquirir papel A4 com selo FSC. & $\mathrm{CPL} / \mathrm{PRADM}$ & $\begin{array}{l}\text { Diretor da Comissão de } \\
\text { Licitação }\end{array}$ & \begin{tabular}{|l|} 
Já está em \\
funcionam \\
ento \\
\end{tabular} & \\
\hline 4 & $\begin{array}{l}\text { Adquirir somente os materiais da } L i s t a \text {, } \\
\text { e, fazer revisões periódicas. }\end{array}$ & $\mathrm{CPL} / \mathrm{PRADM}$ & $\begin{array}{l}\text { Diretor da Comissão de } \\
\text { Licitação }\end{array}$ & 2014 & $\begin{array}{l}\text { Atividade } \\
\text { continua }\end{array}$ \\
\hline 5 & $\begin{array}{l}\text { Redução do uso de copos descartáveis } \\
\text { em todas as unidades da UFC. }\end{array}$ & $\begin{array}{l}\text { Divisão de } \\
\text { Gestão } \\
\text { Ambiental }\end{array}$ & & $\mathrm{Jan} / 14$ & Dez/17 \\
\hline 6 & $\begin{array}{l}\text { Substituição total dos copos } \\
\text { descartáveis por copos de papel. }\end{array}$ & $\mathrm{CPL} / \mathrm{PRADM}$ & $\begin{array}{l}\text { Diretor da Comissão de } \\
\text { Licitação }\end{array}$ & $\mathrm{Jan} / 14$ & Dez/17 \\
\hline 7 & $\begin{array}{l}\text { Redução da produção de agendas } \\
\text { anuais da UFC. }\end{array}$ & \begin{tabular}{|l|} 
Divisão de \\
Gestão \\
Ambiental \\
\end{tabular} & & $\operatorname{Jan} / 14$ & Dez/17 \\
\hline 8 & $\begin{array}{l}\text { Maior agilidade na comunicação. } \\
\text { Menor desperdício. }\end{array}$ & $\begin{array}{l}\text { Todas as } \\
\text { Unidades }\end{array}$ & & $\mathrm{Jan} / 14$ & $\begin{array}{l}\text { Atividade } \\
\text { Contínua }\end{array}$ \\
\hline 9 e 10 & $\begin{array}{l}\text { Redução desperdício de papel, cartucho } \\
\text { e impressoras. Maior facilidade de } \\
\text { acesso aos trabalhos. } \\
\end{array}$ & $\begin{array}{l}\text { Biblioteca } \\
\text { Universitária }\end{array}$ & $\begin{array}{l}\text { Coordenador da } \\
\text { biblioteca }\end{array}$ & $\mathrm{Mar} / 14$ & $\begin{array}{l}\text { Atividade } \\
\text { Contínua }\end{array}$ \\
\hline 11 & $\begin{array}{l}\text { Reduzir o consumo de papel e } \\
\text { cartuchos de impressora. }\end{array}$ & $\begin{array}{l}\text { Todas as } \\
\text { Unidades }\end{array}$ & & $\mathrm{Jan} / 14$ & $\begin{array}{l}\text { Atividade } \\
\text { Contínua }\end{array}$ \\
\hline 12 e 13 & $\begin{array}{l}\text { Aumentar eficiência no consumo de } \\
\text { papel, cartucho e impressoras. }\end{array}$ & $\begin{array}{l}\text { Pró-Reitoria de } \\
\text { Administração }\end{array}$ & $\begin{array}{l}\text { Servidor da Pró-Reitoria } \\
\text { de administração }\end{array}$ & $\mathrm{Jan} / 14$ & $\begin{array}{l}\text { Atividade } \\
\text { Contínua }\end{array}$ \\
\hline
\end{tabular}

Fonte: Plano de Logística Sustentável da UFC, (2013)

De acordo com o Guia de Compras Públicas Sustentáveis para Administração Federal (2010), nesta etapa são selecionados produtos ou famílias de produtos para realização do trabalho, levando-se em consideração o impacto dos produtos no meio ambiente, sua relação com o consumo, a relevância econômica que possuem dentro do sistema de compras públicas.

\subsection{Implantação do plano de ação}

De acordo com que se verificou na etapa qualitativa e quantitativa, a maioria dos entrevistados que trabalharam na elaboração do plano ou possui conhecimento da elaboração do mesmo, acredita que a iniciativa mais relevante para o processo de implantação dos critérios de sustentabilidade foi a criação do PLS.

Antes da elaboração do PLS não havia na universidade pesquisada ações planejadas sobre compras públicas sustentáveis, por tanto, não existe um monitoramento sobre questões relacionadas a sustentabilidade. A universidade não possui informações sobre a quantidade de produtos comprados com critérios de sustentabilidade em determinado período, bem como, 
outro tipo de informação sobre a inclusão dos critérios de sustentabilidade, não faz uso de indicadores no setor de compras.

De acordo com informações que foram identificadas na pesquisa qualitativa e quantitativa as ações ainda não estão sendo totalmente implantadas. Após a construção do plano de logística sustentável, o mesmo foi apresentado à comunidade acadêmica da Universidade Federal do Ceará durante a Semana do Meio Ambiente, sendo tratado como a mais importante iniciativa de gestão ambiental.

A construção do plano de ação depende das etapas anteriores. Como foram deixadas lacunas, o plano de ação que existe em relação às compras públicas sustentáveis da universidade pesquisada, não contempla ações que traduzem a realidade e necessidade do processo e implantação dos critérios de sustentabilidade.

\subsection{Monitoramento progresso e resultados}

A avaliação de desempenho necessita ser dinâmica acessível e fácil, para que desta forma possa auxiliar os gestores no processo de tomada de decisão. Na etapa qualitativa foi perguntado aos entrevistados em relação à necessidade de acompanhamento do processo de implantação de compras, a seguir algumas respostas:

[...] eu acho que os indicadores são a melhor forma pra gente avaliar e não adianta só implementar, na administração agente planeja, organiza e executa só que depois também a gente tem que fazer o controle. O controle é feito mediante o uso de indicadores pelo menos assim eu acredito que é uma das formas mais vantajosas (E3).

[...] trabalhar com monitoramento é interessantíssimo e futuramente dever ser.

Antes da elaboração do PLS não havia ações planejadas sobre compras públicas sustentáveis, por tanto, não existe um monitoramento sobre questões relacionadas a sustentabilidade, a universidade não possui informações sobre a quantidade de produtos compradas com critérios de sustentabilidade em determinado período, bem como, outro tipo de informação sobre a inclusão dos critérios de sustentabilidade, não faz uso de indicadores no setor de compras.

\section{Conclusões}

Este estudo, de caráter exploratório e descritivo, se propôs a analisar o processo de implantação das compras públicas sustentáveis de uma Instituição Federal de Ensino Superior, utilizando a metodologia do ICLEI sugerida pelo governo federal brasileiro como parâmetro.

É possível concluir que a universidade não possui uma política de compras sustentáveis, vem adotando medidas pontuais visando obedecer às normas e leis federais. A pesquisa mostra, 
que os servidores envolvidos no processo de compras da instituição não conseguem identificar as metas e objetivos que poderiam considerar como uma parte de um processo de inclusão de critérios de sustentáveis, apenas os responsáveis pelas licitações de obras e planejamento conseguem reconhecer uma mudança de critérios nas licitações.

A pesquisa de campo apontou que a implantação das compras públicas sustentáveis na UFC se encontra em um estágio inicial. A ação considera de maior impacto foi a criação do Plano de Logística Sustentável, pelo motivo de terem sido traçadas ações de compras e redução de material de consumo, assim como, a criação de uma lista de material de produtos sustentáveis. Assim, espera-se que os resultados apresentados nesta pesquisa possam contribuir cientificamente do ponto de vista acadêmico, por constituir-se um trabalho que vem preencher e dar suporte a trabalhos futuros na agregação de conhecimento sobre a utilização das compras públicas sustentáveis como ferramenta de avaliação e promoção do desenvolvimento e redução dos impactos ambientais causados pelo elevado número de materiais usados no setor público.

Visto que os estudos na área ainda não são suficientes e necessitam de um aprofundamento prático e científico, alguns pontos fundamentais decorrentes deste trabalho que podem ser utilizados em estudos futuros: Estudo das condições do mercado fornecedor de produtos sustentáveis; Desenvolvimento de canais de comunicação com fornecedores, incluindo todos os processos, inclusive armazenamento e distribuição; Análise de todo o processo de compra da instituição com foco na melhoria; Utilização de ferramentas de medição da eficácia das estratégias da organização; Realização estudos sobre a necessidade de capacitação dos servidores envolvidos no processo; Utilização da logística reversa e análise do ciclo de vida no planejamento de ações de sustentabilidade.

\section{REFERÊNCIAS}

BIDERMAN, R., MACEDO, L. S. V., MONZONI, M., MAZON, R., (Orgs.). Guia de Compras Públicas Sustentáveis: uso do poder de compras do governo para promoção do desenvolvimento sustentável. 2. ed. São Paulo: GVces, 2008. Disponível em: <http://www.cqgp.sp.gov.br/gt_licitacoes/publicacoes/Guia-de-compraspublicas-sustent\%C3\%A1veis.pdf>. Acesso em: 14 de abr. 2013.

BRASIL. Constituição da República Federativa do Brasil. Brasília, 1988. Disponível em:<http://www.planalto.gov.br/ccivil_03/constituicao/constituicao.htm>. Acesso em: 22 ago. 2013.

Lei $\mathrm{N}^{\circ} 12.349$, de 15 de dezembro de 2010. Altera as Leis nos 8.666, de 21 de junho de 1993, 8.958, de 20 de dezembro de 1994, e 10.973, de 02 de dezembro de 2004; e revoga o § 1o do art. 2 o da Lei no 11.273, de 6 
de fevereiro de 2006. Diário Oficial [da] República Federativa do Brasil, Brasília, DF, 2010a. Disponível em: <http://www.planalto.gov.br/ccivil_03/_Ato2007-2010/2010/Lei/L12349.htm>. Acesso em 15 abr. 2013.

LEI No 10.520, de 17 de julho de 2002. Institui, no âmbito da União, Estados, Distrito Federal e Municípios, nos termos do art. 37, inciso XXI, da Constituição Federal, modalidade de licitação denominada pregão, para aquisição de bens e serviços comuns, e dá outras providências. Diário Oficial [da] República Federativa do Brasil, Brasília, 2002. Disponível em: http://www.planalto.gov.br/ccivil_03/leis/2002/110520.htm>. Acesso em: 10 abr. 2013.

Lei no 8.666, de 21 de junho de 1993. Regulamenta o art. 37, inciso XXI, da Constituição Federal, institui normas para licitações e contratos da Administração Pública e dá outras providências. Diário Oficial [da] República Federativa do Brasil, Brasília Brasília, 1993. Disponível em: <http://www.planalto.gov.br/ccivil_03/leis/18666cons.htm>. Acesso em: 15 abr. 2013.

Ministério do planejamento, orçamento e gestão. Guia de compras públicas sustentáveis para a Administração Federal. Brasília, 2010. Disponível em:< http://cpsustentaveis.planejamento.gov.br/wpcontent/uploads/2010/06/Cartilha.pdf> Acesso em: 12 fev.2013.

Ministério do planejamento, orçamento e Gestão. Secretaria de logística e tecnologia da informação. Instrução Normativa $\mathrm{n}^{\circ}$. 10, de 12 de novembro de 2012. Estabelece regras para elaboração dos Planos de Gestão de Logística Sustentável de que trata o art.16, do Decreto $\mathrm{n}^{\mathbf{0}}$ 7.746, de 5 de junho de 2012, e dá outras providências. Disponível em: <http://cpsustentaveis.planejamento.gov.br/wpcontent/uploads/2012/11/Instru\%C3\%A7\%C3\%A3o-Normativa-10-2012.pdf>. Acesso em: 20 abr. 2013.

Ministério do Planejamento, orçamento e Gestão. Instrução normativa nº1, de 19 de janeiro de 2010.

Diário Oficial [da] República Federativa do Brasil, Brasília, 2010. Disponível em: $<$ http://cpsustentaveis.planejamento.gov.br/wp-content/uploads/2010/03/Instru\%C3\%A7\%C3\%A3o-Normativa01-10.pdf>. Acesso em: 20 abr. 2013.

Lei $n^{\circ}$ 12.187, de 29 de dezembro de 2009. Institui a Política Nacional sobre Mudança do Clima PNMC e dá outras providências. Diário Oficial [da] República Federativa do Brasil, Brasília, 2009. Disponível em: <http://www.planalto.gov.br/ccivil_03/_ato2007-2010/2009/lei/112187.htm>. Acesso em: 14 jun. 2013.

CARVALHO FILHO, José dos Santos. Manual do Direito Administrativo. 26. ed. São Paulo: Atlas, 2013.

COLLIS, Jill; HUSSEY, Roger. Pesquisa em administração. 2. ed. São Paulo: Bookman, 2005.

GIL, Antonio de Loureiro. Como elaborar projetos de pesquisa. 5. ed. São Paulo, SP: Atlas, 2010.

GOVERNOS LOCAIS PELA SUSTENTABILIDADE. Disponível em: 〈http://www.iclei.org/>. Acesso em: 10 abr. 2013.

ICLEI. Local Governments for Sustainability. The Procura + Manual: A guide to cost effective sustainable public procurement. 2 ed. Friburgo, $2007 . \quad$ Disponível em: <http://www.procuraplus.org/fileadmin/files/Manuals/English_manual/1_-_Procura_Manual_complete.pdf >. Acesso em: 24 abr. 2013.

MARCONI, Marina de Andrade; LAKATOS, Eva Maria. Fundamentos de metodologia científica. 7. ed. São Paulo, SP: Atlas, 2010.

UNIVERSIDADE FEDERAL DO CEARÁ. Comissão gestora do plano de logística sustentável. Planos de gestão de logística sustentável da universidade federal do Ceará. 2013. Disponível em: 
<http://www.ufc.br/images/_files/gestao_ambiental/plano_de_logistica_sustentavel_ufc.pdf>. Acesso em: 19 abr. 2014.

A Universidade. 2014. Disponível em: <http://www.ufc.br/a-universidade>. Acesso em: 22 abr.2014.

Manual de procedimentos de compras e contratações. 2013. Disponível em: <http://www.pradm.ufc.br/images/stories/arquivos/manuais_normas_2013/24.10.2013.pdf>. Acesso em: 15 ago. 2013. 